\title{
A Revised Model of Trust in Internet-Based Health Information and Advice: Cross-Sectional Questionnaire Study
}

\author{
Elizabeth Sillence ${ }^{1}$, PhD; John Matthew Blythe ${ }^{1,2}$, PhD; Pam Briggs ${ }^{1}$, PhD; Mark Moss ${ }^{3}$, PhD \\ ${ }_{1}^{1}$ Psychology and Communication Technology Lab, Department of Psychology, Northumbria University, Newcastle upon Tyne, United Kingdom \\ ${ }^{2}$ Dawes Centre for Future Crime, UCL Jill Dando Institute of Security and Crime Science, University College London, London, United Kingdom \\ ${ }^{3}$ Department of Psychology, Northumbria University, Newcastle upon Tyne, United Kingdom
}

\author{
Corresponding Author: \\ Elizabeth Sillence, $\mathrm{PhD}$ \\ Psychology and Communication Technology Lab \\ Department of Psychology \\ Northumbria University \\ Northumberland Building \\ Newcastle upon Tyne \\ United Kingdom \\ Phone: 4401912437246 \\ Email: elizabeth.sillence@northumbria.ac.uk
}

\begin{abstract}
Background: The internet continues to offer new forms of support for health decision making. Government, charity, and commercial websites increasingly offer a platform for shared personal health experiences, and these are just some of the opportunities that have arisen in a largely unregulated arena. Understanding how people trust and act on this information has always been an important issue and remains so, particularly as the design practices of health websites continue to evolve and raise further concerns regarding their trustworthiness.

Objective: The aim of this study was to identify the key factors influencing US and UK citizens' trust and intention to act on advice found on health websites and to understand the role of patient experiences.

Methods: A total of 1123 users took part in an online survey (625 from the United States and 498 from the United Kingdom). They were asked to recall their previous visit to a health website. The online survey consisted of an updated general Web trust questionnaire to account for personal experiences plus questions assessing key factors associated with trust in health websites (information corroboration and coping perception) and intention to act. We performed principal component analysis (PCA), then explored the relationship between the factor structure and outcomes by testing the fit to the sampled data using structural equation modeling (SEM). We also explored the model fit across US and UK populations.

Results: PCA of the general Web trust questionnaire revealed 4 trust factors: (1) personal experiences, (2) credibility and impartiality, (3) privacy, and (4) familiarity. In the final SEM model, trust was found to have a significant direct effect on intention to act (beta=.59; $P<.001$ ), and of the trust factors, only credibility and impartiality had a significant direct effect on trust (beta=.79; $P<.001)$. The impact of personal experiences on trust was mediated through information corroboration (beta=.06; $P=.04)$. Variables specific to electronic health (eHealth; information corroboration and coping) were found to substantially improve the model fit, and differences in information corroboration were found between US and UK samples. The final model accounting for all factors achieved a good fit (goodness-of-fit index [0.95], adjusted goodness-of-fit index [0.93], root mean square error of approximation [0.50], and comparative fit index [0.98]) and explained $65 \%$ of the variance in trust and $41 \%$ of the variance in intention to act.

Conclusions: Credibility and impartiality continue to be key predictors of trust in eHealth websites. Websites with patient experiences can positively influence trust but only if users first corroborate the information through other sources. The need for corroboration was weaker in the United Kingdom, where website familiarity reduced the need to check information elsewhere. These findings are discussed in relation to existing trust models, patient experiences, and health literacy.
\end{abstract}

(J Med Internet Res 2019;21(11):e11125) doi: 10.2196/11125

\section{KEYWORDS}

trust; eHealth; patient experiences 


\section{Introduction}

\section{Background}

The number of people using the internet for health information and advice continues to grow with people affected by long-term or chronic conditions making particular use of online resources [1]. Over $80 \%$ of teens have sought health information online at some point about a range of health and lifestyle issues [2], and there has been a rise in surrogate seekers, those seeking information online for someone else [3]. Understanding how people come to trust the information and advice they find online has been an important issue since the widespread adoption of the internet [4] and continues to be so (see, eg, recent work by Marcu et al [5] and Lu et al [6]). The explosion in new providers, new formats, and platforms continues to generate concerns regarding the quality and variability of the health information available to the average citizen. Despite the introduction of codes and standards, for example, Health on the Internet code, early concerns over information quality, accuracy, and credibility [7] are still being echoed by researchers examining the provision of electronic health (eHealth) material across a range of conditions [8] including diabetes, osteoarthritis, and orthognathic surgery [9-11]. Today, such concerns sit within a wider debate about the veracity of information available to citizens through a variety of online sources. We know that people will often make snap judgments about the quality of information available online [4,12], relying upon simple heuristics to inform their decision making. We also know that people seldom make these judgments in isolation but are likely to show social influences in their information searches [12]. In particular, we can see that citizens exhibit homophily when going online for information - choosing to be guided by others they perceive as similar to themselves [13] and selecting information that is consistent with their own prior beliefs [14].

These social effects are particularly strong when people share their own health experiences online. Shared personal experiences are important to health consumers $[15,16]$, and these are disseminated in online support communities, which can offer long-term supportive relationships, providing empathy, and reducing patients' sense of isolation $[17,18]$. As online social networks have grown, the range and availability of personal experiences have grown enormously. Peer-to-peer resources in the form of support forums, blogs, written or video testimonials, as well as curated experiences have become a common feature of online health resources. They are found in eHealth sites provided not just by concerned individuals but by charities, governmental organizations, and commercial websites alike. They once again put the concept of a trusting relationship center stage as the mediating technology, the host platform, and the contributors themselves can all be considered as objects of trust [19]. Put simply, a health consumer must typically make a number of layered trust decisions before engaging with peer-led material on a site [13], although a credible host site may be a prerequisite for trust in the more personal stories or blogs contained within [20].

The sheer number of eHealth resources available means that there are significant opportunities to check and verify any information and advice found online. Indeed, corroboration has been shown to have a key role in predicting trust and action around eHealth information [21]. However, research indicates that once again we see different factors influencing the layered trust decisions that are made [21]. At the peer-led level, when people are seeking to check information about personal experiences, these corroborating activities may become distorted by social networks, where the homophily effects of being able to tap into information bubbles of "people like me" may act to limit the effectiveness of cross-checking, particularly for groups with low socioeconomic status (eg, [14]). At the platform or website level, other factors come into play. Thus, for example, many websites require commercial funding, and this in turn can be signaled by the presence of online advertising, which in turn may act to undermine the perceived trustworthiness of the messages on the site. Impartiality is fundamental to trust in online resources [22], and advertising can lead a consumer to question the underlying motivations of an organization, sensing that they may not necessarily be acting primarily in the interests of a patient or carer [23]. Genuine peer contributors to a forum or site may wish to convey a credible, persuasive account of their experience with a particular product or service, but, if the narrative is framed in a commercial context, then the veracity of that experience may be called into question [24,25]. In general, it appears that personal experiences and commerce do not work well together. The blurring of the lines between testimonials and advertising serves to reduce the value of the personal accounts and the overall credibility of the website [23]. Furthermore, new trust concerns arise for both contributors and consumers of health content if people feel that the information they provide or access may be used to profile their own health status. This is a critical issue in the wake of new developments in the United States that give more freedom to internet service providers to sell on consumer information to advertisers [26], making health privacy a critical, but as yet under-researched aspect of trust decision making in eHealth [27].

Understanding the antecedents of trust in online health information has been a long-standing interest of the authors who, for the past 20 years, have developed and reported a number of large-scale eHealth surveys to gauge changes in the trust practices of people seeking health information online. Taken together, the studies have addressed the rise in patient-centered and patient-generated health information.

Since 2000, the range of patient-led resources and the nature and number of different eHealth providers have grown dramatically, and the most recent changes have seen a dramatic rise in patient narratives, often accompanied by new advertising funding models that may not always be viewed as appropriate in a health domain. The noticeable shift toward the inclusion of peer-led information creates interesting questions around what exactly it is that we are being asked to trust-the advice, the patient who provides a story, the organization behind the website, or other (sometimes unknown) funders. All of these can influence the decision to trust, and subsequently act upon, health advice. The extent to which health privacy affects trust in eHealth is also poorly understood. It is, therefore, timely to ask again about how people make their trust decisions. 
Data we collected 10 years ago [21] resulted in a model that showed how trust in eHealth information and intention to act on the advice could be predicted on the basis of source credibility and impartiality. In that study, the predictive value of these 2 factors was enhanced when consumer responses to uncongenial health-risk information was taken into account. In particular, adding variables specific to health psychology (eg, measures addressing coping style), alongside measures designed to capture response to the online environment (eg, information corroboration), enhanced the model's predictive power.

\section{Objectives}

In this study, we aimed to update this model and provide a more timely understanding of the current antecedents of trust in online health information. We did this in 2 steps. First, we assessed the factorial structure of an updated general measure of trust in online health resources. We took the general measure of trust used in the study by Harris et al [21] and supplemented it with measures addressing inter alia personal experiences online, the presence of advertising, and health privacy concerns. Second, we sought to establish how well these subsequent factors improved the predictive power of the older model [21]. In addition, we purposely sampled from the United States and the United Kingdom to establish the robustness of the model across 2 widely different health care economies, one largely privatized (with funding via a complex health insurance network) and the other largely nationalized.

In summary, then, we sought to model the role of online personal experiences in health information and advice-seeking behavior using populations drawn from the United States and the United Kingdom.

\section{Methods}

\section{Design}

A cross-sectional survey was conducted in November 2015 and collected quantitative data from eHealth users regarding their use of health websites as part of a larger project measuring online trust in health websites every 5 years since 2000 . We used a panel company to recruit a similar demographic to those that had participated in our previous studies to gain a sample representative enough to allow for meaningful comparisons.

\section{Participants}

A total of 8272 people clicked on the link from the recruitment advertisement on the panel company's internal Web page and were assessed on their eligibility to take part in the survey. Of this larger sample, $74.62 \%$ (6172/8272) indicated that they used the internet to look for health advice compared with $25.43 \%$ (2103/8272) who did not use the internet for advice. Following eligibility assessment (older than 18 years and UK- [40\% quota] or US-based [60\% quota]), a total of 1396 participants completed the questionnaire. A total of 96 were removed because of incomplete data resulting in 1123 participants that completed the full survey exploring online health seekers. Of the 1123 participants, $875(77.92 \%)$ reported searching the internet for health advice for themselves, 145 (12.91\%) for someone else, and the remaining 112 (9.97\%) for both. Participants received $£ 1.71$ (or the US equivalent) for taking part in the study. Full details of participant demographics can be found in Table 1 . 
Table 1. Participant demographics $(\mathrm{N}=1123)$.

Participant characteristic

Location

United States

United Kingdom

\section{Gender}

Male

Female

Age (years)

$18-24$

25-35

36-44

45-54

$55-64$

$65+$

\section{Employment status}

Full time

Part time

Retired

Unemployed

Student

Marital status

Single

Married

Cohabiting

Civil partnership

Divorced

Widowed

\section{Ethnicity}

White

Latino/Hispanic

Middle Eastern

African

Caribbean

South Asian

East Asian

African American

Mixed

Prefer not to say

\section{Highest level of education}

Less than high school/secondary school

Secondary school/high school/general educational development

Further education (college, A-levels or equivalent)

Bachelor's degree
Online seekers frequency, n (\%)

625 (55.65)

498 (44.34)

462 (41.14)

$661(58.86)$

$172(15.32)$

311 (27.69)

$222(19.77)$

195 (17.36)

$146(13.00)$

$63(5.61)$

$545(48.53)$

$171(15.23)$

137 (12.20)

208 (18.52)

$62(5.52)$

$354(31.52)$

$531(47.28)$

$106(9.44)$

$29(2.58)$

$84(7.48)$

$19(1.69)$

$912(81.21)$

$40(3.56)$

$12(1.07)$

$59(5.25)$

$11(0.98)$

23 (2.05)

$20(1.78)$

$11(0.98)$

$18(1.60)$

$16(1.42)$

$18(1.60)$

294 (26.18)

199 (17.72)

$490(43.63)$ 


\begin{tabular}{ll}
\hline Participant characteristic & Online seekers frequency, $\mathrm{n}(\%)$ \\
\hline Postgraduate degree $(\mathrm{MSc}, \mathrm{PhD})$ & $122(10.86)$ \\
Internet use (years) & $7(0.62)$ \\
$1-2$ & $46(4.10)$ \\
$3-5$ & $98(8.73)$ \\
$6-9$ & $313(27.87)$ \\
$10-14$ & $350(31.17)$ \\
$15-19$ & $309(27.52)$ \\
$20+$ &
\end{tabular}

\section{Procedure}

Before study commencement, the study received full ethical approval from the Department of Psychology at Northumbria University, and the online survey was piloted with 5 participants to assess comprehension and running of the survey. The survey was hosted on Qualtrics. The first page provided participants with information detailing the aim, length, data storage, contact details, and withdrawal process of study. They were then asked to provide informed consent. The study then commenced, and participants were asked whether they used the internet to look for health advice. Those answering "yes" then completed a series of questions relating to the last time they searched for health advice online. Specifically, they were asked to "think about any one site that you visited during that search" and to answer the remaining questions with respect to that site. They answered questions relating to the impact of the health advice on their coping perceptions and intention to act, the degree to which they trusted the information and website, and demographic information.

\section{Measures}

Unless stated otherwise, participants answered the following measures on a 5-point Likert scale ( $1=$ strongly disagree to $5=$ strongly agree $)$.

\section{General Web Trust Questionnaire}

The first measure contained the 24 items from the study by Harris et al [21], supplemented by 8 items assessing the presence of personal experiences [28] and 5 items to measure privacy concerns. In addition, coping was measured with 4 items such as "Looking at this site made me feel in control," in which participants' responses were rated on a 6-point scale with the following labels: 1=less, 2=slightly less, 3=no different, 4=slightly more, and 5=more (Cronbach alpha=.83). Information corroboration with other sources of information was measured with the following 2 items: (1) "I checked other websites" and (2) "I checked other sources" (Cronbach alpha=.85). It is recognized that having just 2 items contributing to a measure can give challenge to the accuracy of Cronbach alpha, although in such cases alpha acts as a lower bound for the reliability, that is, it always underestimates the true reliability of the scale [29]. Note that these items were all taken from an earlier study [21].

\section{Outcome Measures}

Trust was measured with the following 2 items: (1) "I trusted the site" and (2) "I felt I could trust the information on the site" (Cronbach alpha=.78). Intention to act was an outcome measure, assessed with 1 item "I intended to act upon the advice."

\section{Results}

We first explored the updated general Web trust questionnaire by performing principal component analysis (PCA). We then explored the relationship between the factor structure and outcomes by testing its fit to the sampled data using structural equation modeling (SEM).

\section{Properties of the General Web Trust Questionnaire}

The 36 items of the scale were entered into the PCA, and varimax rotation with Kaiser normalization was used. Any items with factor loadings lower than 0.30 were suppressed (see Table 2).

The findings from the PCA revealed that 4 components (with eigenvalues above 1) could explain the data accounting for $66.057 \%$ of the variance. This complied with the minimum acceptable level of $60 \%$ variance and recommendations of eigenvalues above 1 for factors [30]. One item The site was free from advertisements did not load onto any component and was dropped from the analysis. In other words, this component was not, in isolation, a strong enough measure to be considered influential in the final model.

Overall, the analysis revealed that the 4 final components explained a large amount of the variance in the data, and the items had strong component loadings (well above the 0.30 criterion). It is recognized that the fourth component could be considered as weak as it only comprises 2 items. Advice is that there should be a minimum of 3 items per extracted component. However, it is reasonable that a component with 2 items is identified, provided that the other factors have more than 3 items and the 2-item factor has a nonzero covariance with at least one other factor in the population [31]. Such is the case here. 
Table 2. Factor loadings for each item (factor loadings lower than 0.30 are suppressed).

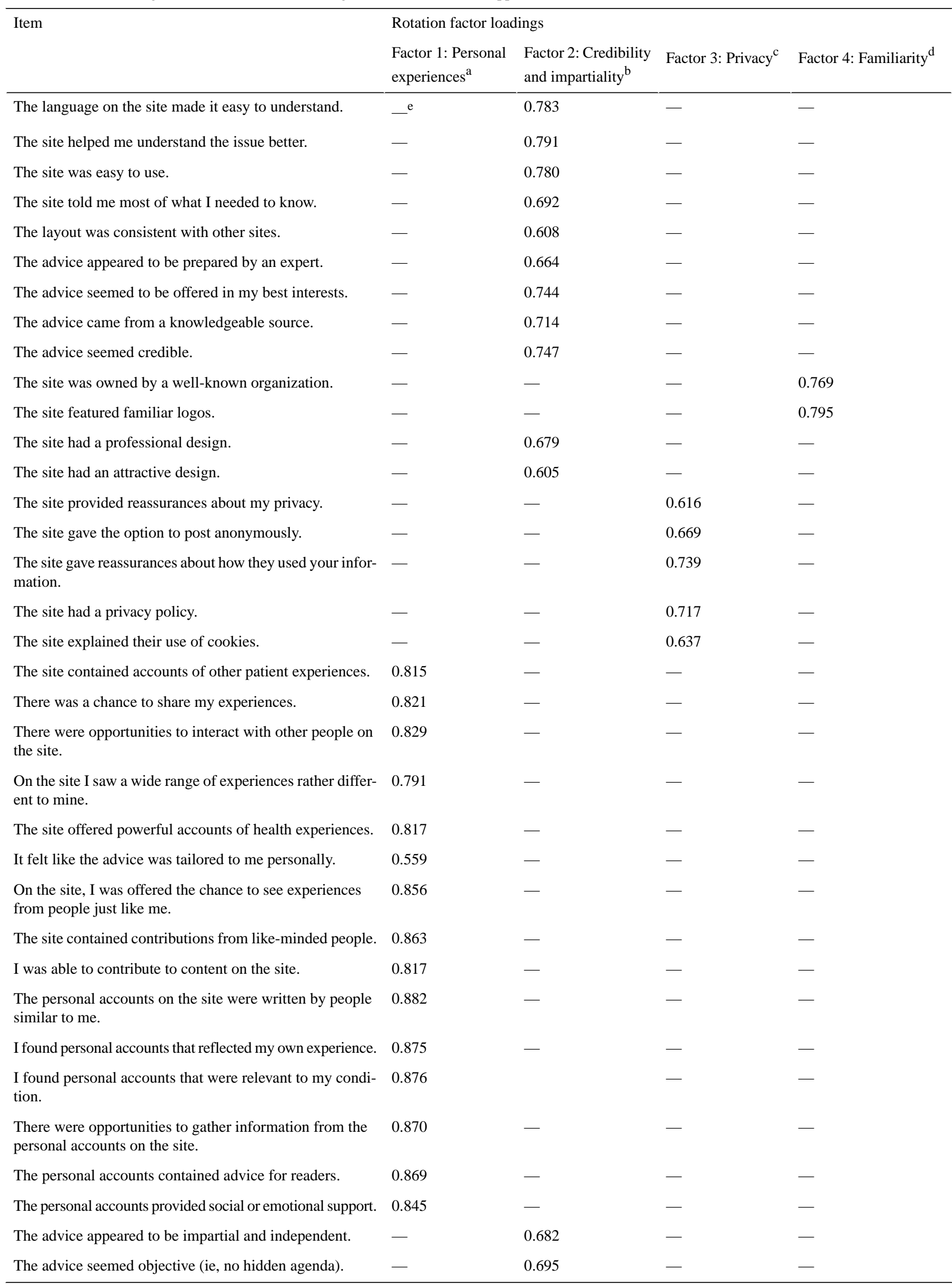




\begin{tabular}{|c|c|c|c|c|}
\hline \multirow[t]{2}{*}{ Item } & \multicolumn{4}{|c|}{ Rotation factor loadings } \\
\hline & $\begin{array}{l}\text { Factor 1: Personal } \\
\text { experiences }^{\mathrm{a}}\end{array}$ & $\begin{array}{l}\text { Factor } 2 \text { : Credibility } \\
\text { and impartiality }\end{array}$ & Factor 3: Privacy ${ }^{\mathrm{c}}$ & Factor 4: Familiarity ${ }^{\mathrm{d}}$ \\
\hline Removed item (the site was free from advertisements). & - & - & - & - \\
\hline
\end{tabular}

${ }^{\mathrm{a}}$ Eigenvalue for factor 1 was 10.849 , and the variance explained was $30.998 \%$.

${ }^{\mathrm{b}}$ Eigenvalue for factor 2 was 7.432 , and the variance explained was $21.234 \%$.

${ }^{\mathrm{c}}$ Eigenvalue for factor 3 was 3.158 , and the variance explained was $3.158 \%$.

${ }^{\mathrm{d}}$ Eigenvalue for factor 4 was 1.681, and the variance explained was $1.681 \%$.

${ }^{\mathrm{e}}$ Not applicable.

\section{Structural Equation Modeling Analysis}

The data were analyzed using SEM performed in IBM SPSS AMOS and based on the model structure from Harris et al [21], which represents the data collected 10 years ago. Maximum likelihood estimation methods were used to assess model fit, and the input for each analysis was the covariance matrix of the items. The goodness-of-fit for the models was evaluated with the following absolute goodness-of-fit indices (GFIs) [32]: (1) the Chi-square goodness-of-fit statistic; (2) the root mean square error of approximation (RMSEA); (3) GFI; (4) the adjusted goodness-of-fit (AGFI), and (5) comparative fit index (CFI). Nonsignificant Chi-square values indicate that the hypothesized model fits the data, and RMSEA values smaller than or equal to 0.08 are indicative of acceptable fit. However, values above 0.1 should lead to model rejection [33]. GFI values greater than 0.95 are indicative of good fit, and values greater than 0.90 are indicative of an acceptable fit [34]. AGFI values of 0.90 are indicative of a good fit, and values greater than 0.85 may be considered an acceptable fit [35]. The closer the CFI value is to 1 the better the fit [36].

The final model accounted for $65 \%$ of the variance in trust, $27 \%$ of the variance in coping, and $41 \%$ of the variance in intention to act. The model was a good fit for 4 of the indices. The fit indices for GFI and AGFI were 0.95 and 0.93, which are indicative of a good fit. RMSEA was 0.050, and CFI was 0.98. Path coefficients (beta) and $\mathrm{R}^{2}$ values were also inspected in evaluating the predictive power of the models. Although the Chi-square indicated that the model was not a good fit to the data, $X_{168}^{2}=639.8, P<.001$, Chi-square has been criticized for being too sensitive to large sample sizes, especially for samples over 200 [37], as in this study.

Only credibility and impartiality was found to have a significant, direct relationship with trust (see Table 3). Familiarity and presence of personal experiences did not significantly relate to trust. The effects of familiarity, personal experiences, and privacy may be indirect and mediated through the other trust variables. In particular, personal experiences was found to have a significant direct effect on information corroboration, which in turn significantly predicted trust. Individuals who are presented with personal experiences may, therefore, corroborate this information with other sources and websites enhancing their trust in the personal experiences account. Trust in turn was found to significantly relate to coping perceptions and intention to act on the advice. This suggests that trustworthy websites heighten their coping perceptions, making them feel reassured, in control, and able to cope.

Table 3. The regression weights and critical ratio (ie, Z-score) values for the main effects of the hypothesized full model (combined UK and US participants).

\begin{tabular}{llll}
\hline Parameter & Unstandardized path coefficients & Critical ratio & $P$ value \\
\hline Credibility and impartiality $\rightarrow$ trust & 0.944 & 17.110 & $<.001$ \\
Familiarity $\rightarrow$ trust & 0.012 & 0.552 & .58 \\
PEX $\rightarrow$ trust & 0.021 & 0.960 & .34 \\
Information corroboration $\rightarrow$ trust & 0.050 & 3.001 & .003 \\
Credibility and impartiality $\rightarrow$ information corroboration & 0.520 & 7.566 & $<.001$ \\
Familiarity $\rightarrow$ information corroboration & -0.051 & -1.289 & .20 \\
PEX $\rightarrow$ information corroboration & 0.067 & 2.092 & .04 \\
Trust $\rightarrow$ coping & 2.229 & 16.518 & $<.001$ \\
Trust $\rightarrow$ intention to act & 0.794 & 16.197 & $<.001$ \\
Coping $\rightarrow$ intention to act & 0.013 & 1.425 & .15 \\
Information corroboration $\rightarrow$ intention to act & 0.063 & 2.751 & .006 \\
\hline
\end{tabular}

${ }^{\mathrm{a} P E X}$ : personal experiences. 


\section{Comparison of Two Populations}

A total of 2 further structural equation models were then assessed; one for each of the 2 populations that made up the full dataset, those from the United States and those from the United Kingdom. Although no previous literature exists to document consumer differences in terms of their trust in online health information, the countries differ widely in terms of state-run health provision, and it is known that health consumers differ in terms of their internet health behaviors [38] and that physicians in the United States and the United Kingdom differ widely in terms of their access to online information [39].

\section{US Population}

The model was a good fit for 4 of the indices. The GFI and AGFI were 0.93 and 0.91 , respectively, and the RMSEA and CFI were 0.055 and 0.97 , respectively, although the Chi-square indicated that the model was not a good fit to the data, $\mathrm{X}^{2}{ }_{168}=481.3, P<.001$ (see earlier above). Path coefficients (beta) and $\mathrm{R}^{2}$ values were also inspected in evaluating the predictive power of the models. The final model accounted for $64 \%$ of the variance in trust, $27 \%$ of the variance in coping, and $44 \%$ of the variance in intention to act. Regression weights are presented in Table 4 below.

Table 4. The regression weights and critical ratio values for the main effects of the hypothesized model for US participants.

\begin{tabular}{llll}
\hline Parameter & Unstandardized path coefficients & Critical ratio & $P$ value \\
\hline Credibility and impartiality $\rightarrow$ trust & 1.001 & 13.346 & $<.001$ \\
Familiarity $\rightarrow$ trust & -0.052 & -1.515 & .13 \\
PEX $\rightarrow$ trust & 0.073 & 2.436 & .02 \\
Information corroboration $\rightarrow$ trust & 0.068 & 3.023 & .003 \\
Credibility and impartiality $\rightarrow$ information corroboration & 0.364 & 3.959 & $<.001$ \\
Familiarity $\rightarrow$ information corroboration & 0.018 & 0.308 & .76 \\
PEX $\rightarrow$ information corroboration & 0.060 & 1.408 & .16 \\
Trust $\rightarrow$ coping & 2.224 & 12.696 & $<.001$ \\
Trust $\rightarrow$ intention to act & 0.802 & 13.216 & $<.001$ \\
Coping $\rightarrow$ intention to act & 0.008 & 0.651 & .52 \\
Information corroboration $\rightarrow$ intention to act & 0.075 & 2.485 & .01
\end{tabular}

${ }^{\text {a}}$ PEX: personal experiences.

There are 2 differences in the observed relationships when comparing the US model with the full model. First, the significant predictive path between personal experiences and information corroboration is lost. However, given that the regression weight is identical in both models, this is just a consequence of reduced power in the US analysis. More notable is the introduction of a significant path between personal experiences and trust that is not evident in the full model. All other paths are comparable between the 2 models.

\section{UK Population}

Although the Chi-square indicated that the model was not a good fit to the data, $X^{2}{ }_{168}=422.8, P<.001$, the model was a good fit for the remaining 4 indices. The GFI and AGFI were 0.92 and 0.89 , respectively. Finally, RMSEA was 0.055, and CFI was 0.97 . Path coefficients (beta) and $\mathrm{R}^{2}$ values were also inspected in evaluating the predictive power of the models. The final model accounted for $65 \%$ of the variance in trust, $27 \%$ of the variance in coping, and $38 \%$ of the variance in intention to act. Regression weights are presented in Table 5.

As with the US-based model, the significant predictive path between personal experiences and information corroboration is lost. Equally, however, the regression weight is identical in both models, and this is just a consequence of reduced power in the UK analysis. A total of 2 further paths also fail to reach significance in the UK model compared with the full model: information corroboration to trust and to intention to act. For these 2 , there is a noticeable reduction in the regression coefficients for the UK model compared with both the US and full models, and as such the loss of significance is a consequence of a weaker relationship as well as a reduction in power. Moreover, the UK model also produces a significant path between familiarity and information corroboration that is not present in either the full or the US model.

In summary, although the US- and UK-based analyses share-as might be expected-many of the significant relationships identified in the full model, 2 distinct dissociations are also identified: The significant path between personal experiences and trust that only emerges in the US model and the significant (and negative) path between familiarity and information corroboration that only emerges in the UK model, such that UK citizens are less likely to corroborate information if their primary source is familiar. 
Table 5. The regression weights and critical ratio values for the main effects of the hypothesized model for UK participants.

\begin{tabular}{llll}
\hline Parameter & Unstandardized path coefficients & Critical ratio & $P$ value \\
\hline Credibility and impartiality $\rightarrow$ trust & 0.912 & 10.982 & $<.001$ \\
Familiarity $\rightarrow$ trust & 0.034 & 1.135 & .26 \\
PEX $\rightarrow$ trust & -0.031 & -0.985 & .33 \\
Information corroboration $\rightarrow$ trust & 0.029 & 1.141 & .25 \\
Credibility and impartiality $\rightarrow$ information corroboration & 0.740 & 7.094 & $<.001$ \\
Familiarity $\rightarrow$ information corroboration & -0.139 & -2.586 & .01 \\
PEX information corroboration & 0.065 & 1.337 & .18 \\
Trust $\rightarrow$ coping & 2.213 & 10.716 & $<.001$ \\
Trust $\rightarrow$ intention to act & 0.782 & 9.929 & $<.001$ \\
Coping $\rightarrow$ intention to act & 0.019 & 1.259 & .21 \\
Information corroboration $\rightarrow$ intention to act & 0.058 & 1.656 & .02 \\
\hline
\end{tabular}

${ }^{\mathrm{a}} \mathrm{PEX}$ : personal experiences.

\section{Discussion}

\section{Principal Findings}

In terms of identifying the key predictors of trust and intention to act on health information, we found that trust significantly influenced self-reported intention to act on advice. Of the trust predictors, only credibility and impartiality was found to have a significant, direct relationship with trust. The effects of other variables (familiarity, personal experiences, and privacy) may be indirect and mediated through the other trust variables. For the role of personal experiences, it was found to have a significant direct effect on information corroboration, which in turn significantly predicted trust. Trust in turn was found to significantly relate to coping perceptions and intention to act on the advice. These results lead us to make the following observations.

The first point to note is that trust judgments significantly influence self-reported intention to act upon the health advice given online and furthermore, that these trust judgments reflect the extent to which people feel that the information sources are (1) credible, that is, contain good quality, relevant information, (2) well designed and presented, and (3) impartial, that is, contain information offered in the health consumer's best interest. These results resonate with recent findings in the existing literature (see Sbaffi and Rowley [40] for a systematic review). For example, trust is known to predict intention to act upon health advice (eg, [21,41]). The relevance, quality, usefulness, and accuracy of information are known determinants that the information content is trustworthy [42]. The presentation, ease of use, and clarity of information are linked to perceptions of professionalism that, again, underpin judgments of trust $[4,43,44]$ and, finally, the beliefs about objectivity and impartiality of the source also ensure trust [21].

Looking in more detail at the model presented in Figure 1, we can see interesting similarities and differences between the current model and the model developed 10 years ago [21]. Specifically, Harris et al [21] showed that 2 website factors (information quality and impartiality) directly influenced trust.
In the model we present here, these same 2 website factors, now combined into 1 construct named credibility and impartiality are the strongest predictors of trust. Harris et al [21] also showed that trust and its relationship to intention to act were moderated by 2 cognitive processes-involving threat appraisal and information corroboration. They also, along with personal experiences factor, significantly affect the processes of information corroboration, which in turn affect both trust and intention to act upon the health advice given, with a final coping factor also moderating the relationship between trust and intention to act. In short, credibility of information and impartiality occupy pivotal roles in our decision to trust the information we view online, as it did in the earlier Harris et al model [21], something entirely consistent with the ways in which patients come to develop trust relationships with their physician where there is a strong belief that doctors act in the patients' best interest (eg, [45]). Credibility and impartiality are key to trust in eHealth in 2019 as they were 10 years ago.

Online health information is also important in helping people to cope with health issues. When people trust sites that provide positive information about controlling symptoms or disease, it appears to help boost their overall sense of coping and efficacy. Although the model developed by Harris et al [21] did not find a significant relationship between trust and coping, we found that trust could account for $27 \%$ of the variance in coping. Our model confirms that placing trust in health websites is important in helping users to cope with their health issues, and this is in line with previous research indicating that seeking health information is in itself an important coping mechanism in enhancing adjustment to illness and in the promotion of health-related activities [46,47]. These findings could reflect a general improvement in the ways in which trusted sites offer information and advice and is possibly related to the rise of health websites offering patient experiences. We know from these data that patient experiences can influence trust (see below), and from the published literature, we know that personal experiences can also help people to feel supported in their health issues [18], but the ways that such experiences might directly affect coping would require further investigation. 
Figure 1. The trust model with significant standardized path coefficients. PEX: personal experiences.

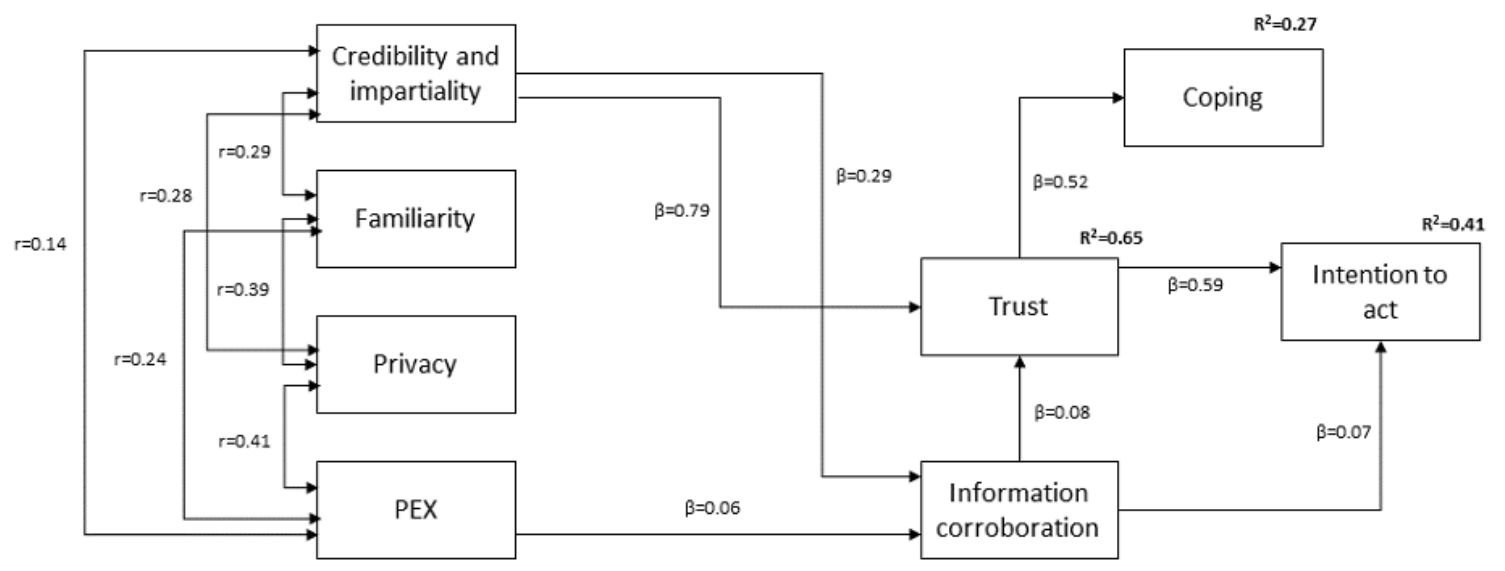

The role of personal experiences in relation to trust is an interesting finding, and our contribution here is novel. As we noted earlier, one of the biggest changes to the internet is the sharing of patient stories and experiences. We note in our model that personal experiences can influence trust but only indirectly through first, influencing those judgments of credibility and impartiality that are so important in predicting trust and second, influencing the ways that people choose to corroborate the information they view online. This finding resonates with the idea that although personal experiences are often liked, they are not necessarily trusted automatically [23]. The literature concerning trust in ecommerce and, in particular, social commerce provides a useful reference point for considering the relationship between trust in personal experiences and trust in the health website overall $[48,49]$. The trustworthiness of other customers on a website can be transferred to the community and thus help build stronger confidence or trust in the website as a whole [50]. Similarly, on social media sites, high levels of trust in other site members lead to higher levels of trust in and use of the site as a whole [51].

The corroboration point is interesting as in the combined UK and US data we found that low information credibility and impartiality, as well as the presence of personal experiences, led to higher levels of corroboration but that the need for corroboration, sometimes referred to as triangulation, differed between the US and UK samples. Specifically, in the United Kingdom, if the primary source of information was familiar, then patients expressed less need to corroborate that information. This could well be a function of the dominance of the National Health Service as a single trusted health care provider in the United Kingdom (indeed, most UK respondents cited the National Health Service website as their source of health information), as opposed to the more complex marriage of public and private insurance-based systems operating in the United States, where WebMD was the most popular online choice. It may also be possible that the difference could lie in the extent to which advertising was present in the most popular websites, but our single item on advertising was insufficient to provide good data here. These results do resonate with the data provided by Schneider et al [38] who compared eHealth search patterns in a private (United States) and public (United Kingdom) health care market and concluded that the US system incentivizes personal search into eHealth and that free access to health care professionals in the United Kingdom (including telephone support) reduces the incentive to search widely for health information online.

The health corroboration process relies upon people being able to make an appropriate distinction between the more or less reliable sources of information they find online, and of course people may differ in their ability to make this distinction and to retain it when trying to recall information at a later date. The extent to which individuals engage in information corroboration is likely to reflect eHealth literacy and suggest that we may need to think more carefully about how to support different individuals when making trust judgments about online health information [14,52]. This may be particularly important when personal experiences are present as we know that personal experiences can help trigger a homophily "patients like me" response that may mean individuals are yet more vulnerable to targeted messages [13].

Health privacy was introduced as a factor in this study. It did not impact directly on trust in eHealth information, but the effect of privacy may be indirect and mediated through other trust variables. The data for this study were collected before the introduction of new privacy and data protection legislation that regulates the storage of personal data. The General Data Protection Regulation in Europe, which came into force in May 2018, is designed to harmonize data protection law across Europe and to bring the law up to date with technological advancements, specifically the increasing use of digital data. It would be interesting to see how a more transparent and direct message about data processing may impact on people's perceptions of data privacy with regard to health websites going forward, and in the wake of increasing public concerns about the privacy of their health data, it is interesting to note new models that speculate on the role of health privacy in eHealth [53].

\section{Limitations and Future Work}

Here we focus on a sample of the US and UK population, which limits how representative the findings are to other countries and cultures. Nevertheless, the model demonstrates the impact of trust in eHealth on health decision making for 2 different westernized countries (with different national health practices) 
and where use of the internet and technology is widespread. However, further work is required to explore country and demographic differences such as the growing role of information credibility skills in navigating online information [54]. Second, future work would benefit from assessing the impact of advertising using a more comprehensive range of items.

We speculated that corroboration across online sources may be linked to advertising, but the single advertising item within the general trust questionnaire did not load onto any of the factors in the model. It may still be worth exploring this relationship in future work as it may point to a changing and increasingly complex situation concerning the form and presence of advertising on health websites. Advertising comes in many forms, from banners to embedded endorsements. Pharmaceutical sites offer a holistic form of advertising, although some sites may choose to advertise through the use of crafted personal testimonials. The single item assessing advertising may be too blunt an instrument to detect attitudes toward these different commercial approaches and limits what we can deduce about the effect of advertising on trust in eHealth. The work is underway to assess people's understanding of advertising more broadly in this context, especially given the blending of information sources in an online health care context [55].

\section{Conclusions}

In conclusion, despite the large increase in new providers, new formats, and platforms, impartiality continues to remain a key predictor of trust in health websites as well as the extent to which users consider information sources to be credible. The presence of personal experiences information can have a positive influence on trust provided that users corroborate the information through additional sources.

\section{Conflicts of Interest}

None declared.

\section{References}

1. Fox S, Duggan M, Purcell K. Pew Research Center. 2013 Jun 20. Family Caregivers are Wired for Health URL: https:/ /www.pewinternet.org/2013/06/20/family-caregivers-are-wired-for-health/ [accessed 2019-10-24]

2. Wartella E, Rideout V, Montague H, Beaudoin-Ryan L, Lauricella A. Teens, health and technology: a national survey. Media Commun 2016;4(3):13. [doi: 10.17645/mac.v4i3.515]

3. Cutrona SL, Mazor KM, Vieux SN, Luger TM, Volkman JE, Finney Rutten LJ. Health information-seeking on behalf of others: characteristics of 'surrogate seekers'. J Cancer Educ 2015 Mar;30(1):12-19 [FREE Full text] [doi: 10.1007/s13187-014-0701-3] [Medline: 24989816]

4. Sillence E, Briggs P, Harris PR, Fishwick L. How do patients evaluate and make use of online health information? Soc Sci Med 2007 May;64(9):1853-1862. [doi: 10.1016/j.socscimed.2007.01.012] [Medline: 17328998]

5. Marcu A, Black G, Whitaker KL. Variations in trust in Dr Google when experiencing potential breast cancer symptoms: exploring motivations to seek health information online. Health Risk Soc 2018;20(7-8):325-341. [doi: $10.1080 / 13698575.2018 .1550742]$

6. Lu X, Zhang R, Wu W, Shang X, Liu M. Relationship between internet health information and patient compliance based on trust: empirical study. J Med Internet Res 2018 Aug 17;20(8):e253 [FREE Full text] [doi: 10.2196/jmir.9364] [Medline: 30120087]

7. Eysenbach G, Powell J, Kuss O, Sa E. Empirical studies assessing the quality of health information for consumers on the world wide web: a systematic review. J Am Med Assoc 2002;287(20):2691-2700. [doi: 10.1001/jama.287.20.2691] [Medline: $\underline{12020305]}$

8. Daraz L, Morrow AS, Ponce OJ, Farah W, Katabi A, Majzoub A, et al. Readability of online health information: a meta-narrative systematic review. Am J Med Qual 2018;33(5):487-492. [doi: 10.1177/1062860617751639] [Medline: 29345143]

9. Guan Y, Maloney KA, Roter DL, Pollin TI. Evaluation of the informational content, readability and comprehensibility of online health information on monogenic diabetes. J Genet Couns 2018 Jun;27(3):608-615 [FREE Full text] [doi: 10.1007/s10897-017-0155-y] [Medline: 28951986]

10. Barrow A, Palmer S, Thomas S, Guy S, Brotherton J, Dear L, et al. Quality of web-based information for osteoarthritis: a cross-sectional study. Physiotherapy 2018 Sep;104(3):318-326. [doi: 10.1016/j.physio.2018.02.003] [Medline: 30030036]

11. Lee KC, Berg ET, Jazayeri HE, Chuang S, Eisig SB. Online patient education materials for orthognathic surgery fail to meet readability and quality standards. J Oral Maxillofac Surg 2019 Jan;77(1):180.e1-180.e8. [doi: 10.1016/j.joms.2018.08.033] [Medline: 30296407]

12. Metzger MJ, Flanagan AJ, Medders RB. Social and heuristic approaches to credibility evaluation online. J Commun 2010;60(3):413-439. [doi: 10.1111/j.1460-2466.2010.01488.x]

13. Sillence E, Hardy C, Harris PR, Briggs P. Modeling Patient Engagement in Peer-to-Peer Healthcare. In: Proceedings of the 23rd International Conference on World Wide Web. 2014 Presented at: WWW'14 Companion; April 7-11, 2014; Seoul, Korea p. 481-486. [doi: 10.1145/2567948.2576937]

14. Perez SL, Kravitz RL, Bell RA, Chan MS, Paterniti DA. Characterizing internet health information seeking strategies by socioeconomic status: a mixed methods approach. BMC Med Inform Decis Mak 2016 Aug 9;16:107 [FREE Full text] [doi: 10.1186/s12911-016-0344-x] [Medline: 27506607] 
15. Lovatt M, Bath PA, Ellis J. Development of trust in an online breast cancer forum: a qualitative study. J Med Internet Res 2017 May 23;19(5):e175 [FREE Full text] [doi: 10.2196/jmir.7471] [Medline: 28536093]

16. Brady E, Segar J, Sanders C. 'You get to know the people and whether they're talking sense or not': negotiating trust on health-related forums. Soc Sci Med 2016 Aug;162:151-157 [FREE Full text] [doi: 10.1016/j.socscimed.2016.06.029] [Medline: 27359321]

17. Rozmovits L, Ziebland S. What do patients with prostate or breast cancer want from an Internet site? A qualitative study of information needs. Patient Educ Couns 2004 May;53(1):57-64. [doi: 10.1016/S0738-3991(03)00116-2] [Medline: 15062905]

18. Ziebland S, Wyke S. Health and illness in a connected world: how might sharing experiences on the internet affect people's health? Milbank Q 2012 Jul;90(2):219-249 [FREE Full text] [doi: 10.1111/j.1468-0009.2012.00662.x] [Medline: 22709387]

19. Grabner-Kräuter S. Web 2.0 social networks: the role of trust. J Bus Ethics 2010 Aug;90(S4):505-522. [doi: $10.1007 / \mathrm{s} 10551-010-0603-1]$

20. $\mathrm{Hu} \mathrm{Y,} \mathrm{Shyam} \mathrm{Sundar} \mathrm{S.} \mathrm{Effects} \mathrm{of} \mathrm{online} \mathrm{health} \mathrm{sources} \mathrm{on} \mathrm{credibility} \mathrm{and} \mathrm{behavioral} \mathrm{intentions.} \mathrm{Commun} \mathrm{Res}$ 2010;37(1):105-132. [doi: 10.1177/0093650209351512]

21. Harris PR, Sillence E, Briggs P. Perceived threat and corroboration: key factors that improve a predictive model of trust in internet-based health information and advice. J Med Internet Res 2011 Jul 27;13(3):e51 [FREE Full text] [doi: 10.2196/jmir.1821] [Medline: 21795237]

22. Powell J, Inglis N, Ronnie J, Large S. The characteristics and motivations of online health information seekers: cross-sectional survey and qualitative interview study. J Med Internet Res 2011 Mar 23;13(1):e20 [FREE Full text] [doi: 10.2196/jmir.1600] [Medline: 21345783 ]

23. Sillence E, Hardy C, Briggs P. Why Don't We Trust Health Websites That Help Us Help Each Other?: An Analysis of Online Peer-to-Peer Healthcare. In: Proceedings of the 5th Annual ACM Web Science Conference. 2013 Presented at: WebSci'13; May 2-4, 2013; Paris, France p. 396-404. [doi: 10.1145/2464464.2464488]

24. Vance K, Howe W, Dellavalle RP. Social internet sites as a source of public health information. Dermatol Clin 2009 May;27(2):133-6, vi. [doi: 10.1016/j.det.2008.11.010] [Medline: 19254656]

25. Hohm C, Snyder J. 'It Was the Best Decision of My Life': a thematic content analysis of former medical tourists' patient testimonials. BMC Med Ethics 2015 Jan 22;16:8 [FREE Full text] [doi: 10.1186/1472-6939-16-8] [Medline: 25614083]

26. Brewster T. Forbes. 2017 Mar 30. Now Those Privacy Rules Are Gone, This Is How ISPs Will Actually Sell Your Personal Data URL: https://www.forbes.com/sites/thomasbrewster/2017/03/30/fcc-privacy-rules-how-isps-will-actually-sell-your-data/ $\# 741$ fe40e21d1 [accessed 2019-10-24]

27. Kim Y. Trust in health information websites: a systematic literature review on the antecedents of trust. Health Informatics J 2016 Jun;22(2):355-369. [doi: 10.1177/1460458214559432] [Medline: 25518944]

28. Sillence L, Mo P, Briggs P, Harris PR. The Changing Face of Trust in Health Websites. SSRN Journal 2011:-. [doi: 10.2139/ssrn.1920317]

29. Eisinga R, Grotenhuis MT, Pelzer B. The reliability of a two-item scale: Pearson, Cronbach, or Spearman-Brown? Int J Public Health 2013 Aug;58(4):637-642. [doi: 10.1007/s00038-012-0416-3] [Medline: 23089674]

30. Hinkin TR. A brief tutorial on the development of measures for use in survey questionnaires. Organ Res Methods 1998;1(1):104-121. [doi: 10.1177/109442819800100106]

31. Yong AG, Pearce S. A beginner's guide to factor analysis: focusing on exploratory factor analysis. Tutor Quant Methods Psychol 2013;9(2):79-94. [doi: 10.20982/tqmp.09.2.p079]

32. Jöreskog KG, Sörbom D. LISREL VI: Analysis of Linear Structural Relationships by Maximum Likelihood, Instrumental Variables, and Least Squares Methods, Users Guide. Mooresville, Indiana: Scientific Software; 1986.

33. Browne MW, Cudeck R. Alternative ways of assessing model fit. Soc Methods Res 1992;21(2):230-258. [doi: $10.1177 / 0049124192021002005]$

34. Marsh H, Grayson D. Latent variable models of multitrait-multimethod data. In: Hoyle R, editor. Structural Equation Modeling: Concepts, Issues, and Applications. Thousand Oaks, CA: Sage; 1995:177-198.

35. Hu L, Bentler P. Evaluating model fit. In: Hoyle R, editor. Structural Equation Modeling: Concepts, Issues, and Applications. Thousand Oaks, CA: Sage; 1995:76-99.

36. Garson GD. Faculty and Staff - NC State. 2009. Statnotes: Topics in Multivariate Analysis URL: https://faculty. chass.ncsu.edu/garson/PA765/statnote.htm [accessed 2019-10-31]

37. Hoe S. Issues and procedures in adopting structural equation modeling technique. J Appl Quant Methods 2008;3(1):76-83 [FREE Full text]

38. Schneider JA, Holland CP. eHealth search patterns: a comparison of private and public health care markets using online panel data. J Med Internet Res 2017 Apr 13;19(4):e117 [FREE Full text] [doi: 10.2196/jmir.6739] [Medline: 28408362]

39. Davies KS. Physicians and their use of information: a survey comparison between the United States, Canada, and the United Kingdom. J Med Libr Assoc 2011 Jan;99(1):88-91 [FREE Full text] [doi: 10.3163/1536-5050.99.1.015] [Medline: 21243061]

40. Sbaffi L, Rowley J. Trust and credibility in web-based health information: a review and agenda for future research. J Med Internet Res 2017 Jun 19;19(6):e218 [FREE Full text] [doi: 10.2196/jmir.7579] [Medline: 28630033] 
41. Sheng X, Simpson PM. Health care information seeking and seniors: determinants of Internet use. Health Mark Q 2015;32(1):96-112. [doi: 10.1080/07359683.2015.1000758] [Medline: 25751321]

42. Corritore CL, Wiedenbeck S, Kracher B, Marble RP. Online trust health information websites. Int J Technol Hum Interact 2012;8(4):92-115. [doi: 10.4018/jthi.2012100106]

43. Johnson F, Rowley J, Sbaffi L. Modelling trust formation in health information contexts. J Inf Sci 2015;41(4):415-429. [doi: 10.1177/0165551515577914]

44. Fisher J, Burstein F, Lynch K, Lazarenko K. 'Usability + usefulness = trust': an exploratory study of Australian health web sites. Internet Res 2008 Oct;18(5):477-498. [doi: 10.1108/10662240810912747]

45. Hall MA, Zheng B, Dugan E, Camacho F, Kidd KE, Mishra A, et al. Measuring patients' trust in their primary care providers. Med Care Res Rev 2002 Oct;59(3):293-318. [doi: 10.1177/1077558702059003004] [Medline: 12205830]

46. Medlock S, Eslami S, Askari M, Arts DL, Sent D, de Rooij SE, et al. Health information-seeking behavior of seniors who use the internet: a survey. J Med Internet Res 2015 Jan 8;17(1):e10 [FREE Full text] [doi: 10.2196/jmir.3749] [Medline: 25574815]

47. Lambert SD, Loiselle CG. Health information seeking behavior. Qual Health Res 2007 Oct;17(8):1006-1019. [doi: 10.1177/1049732307305199] [Medline: 17928475]

48. Kim DJ. Self-perception-based versus transference-based trust determinants in computer-mediated transactions: a cross-cultural comparison study. J Manag Inf Syst 2008;24(4):13-45. [doi: 10.2753/mis0742-1222240401]

49. Chow WS, Shi S. Understanding Consumer Trust in Social Commerce Websites. In: Proceedings of 18th Pacific Asia Conference on Information Systems. 2014 Presented at: PACIS'14; June 24-28, 2014; Chengdu, China.

50. Ng CS. Intention to purchase on social commerce websites across cultures: a cross-regional study. Inf Manag 2013;50(8):609-620. [doi: 10.1016/j.im.2013.08.002]

51. Valenzuela S, Park N, Kee KF. Is there social capital in a social network site?: Facebook use and college students' life satisfaction, trust, and participation. J Comput Mediat Commun 2009;14(4):875-901. [doi: 10.1111/j.1083-6101.2009.01474.x]

52. Paige SR, Krieger JL, Stellefson ML. The influence of eHealth literacy on perceived trust in online health communication channels and sources. J Health Commun 2017 Jan;22(1):53-65 [FREE Full text] [doi: 10.1080/10810730.2016.1250846] [Medline: 28001489]

53. Shen N, Strauss J, Silver M, Carter-Langford A, Wiljer D. The eHealth trust model: a patient privacy research framework. In: Lau F, Bartle-Clar JA, Bliss J, Borycki EM, Courtney KL, editors. Improving Usability, Safety and Patient Outcomes with Health Information Technology. Amsterdam: IOS Press; 2019:382-387.

54. Armstrong-Heimsoth A, Johnson ML, McCulley A, Basinger M, Maki K, Davison D. Good Googling: a consumer health literacy program empowering parents to find quality health information online. J Consum Health Internet 2017;21(2):111-124. [doi: $10.1080 / 15398285.2017 .1308191]$

55. Sullivan HW, O'Donoghue AC, Rupert DJ, Willoughby JF, Amoozegar JB, Aikin KJ. Are disease awareness links on prescription drug websites misleading? A randomized study. J Health Commun 2016 Nov;21(11):1198-1207. [doi: 10.1080/10810730.2016.1237594] [Medline: 27805473]

\section{Abbreviations}

AGFI: adjusted goodness-of-fit

CFI: comparative fit index

eHealth: electronic health

GFI: goodness-of-fit index

PCA: principal component analysis

RMSEA: root mean square error of approximation

SEM: structural equation modeling

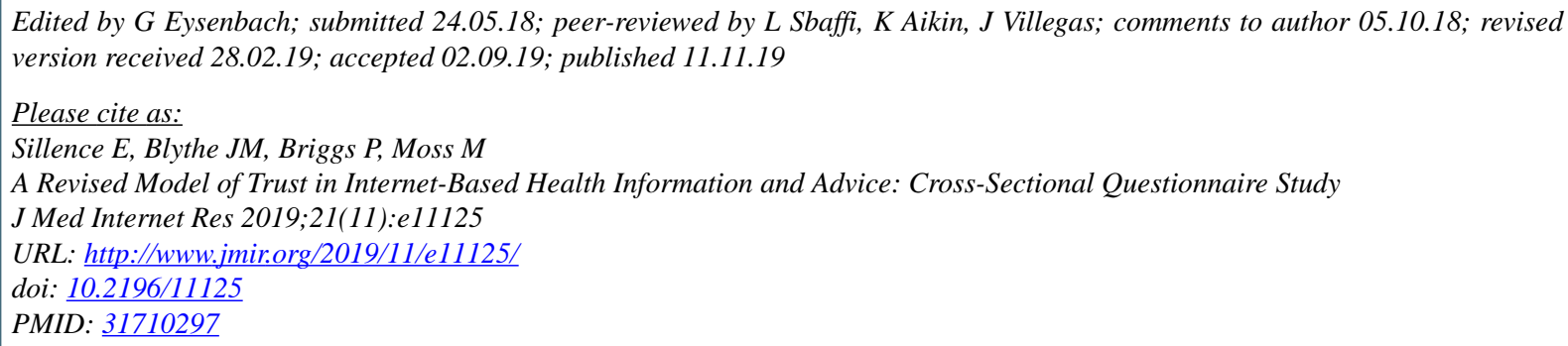


CElizabeth Sillence, John Matthew Blythe, Pam Briggs, Mark Moss. Originally published in the Journal of Medical Internet Research (http://www.jmir.org), 11.11.2019. This is an open-access article distributed under the terms of the Creative Commons Attribution License (https://creativecommons.org/licenses/by/4.0/), which permits unrestricted use, distribution, and reproduction in any medium, provided the original work, first published in the Journal of Medical Internet Research, is properly cited. The complete bibliographic information, a link to the original publication on http://www.jmir.org/, as well as this copyright and license information must be included. 